\title{
As Oficinas Terapêuticas e a Lógica do Cuidado Psicossocial: Concepções dos(as) Coordenadores(as)
}

\author{
Ana Luiza de Mendonça Oliveira ${ }^{1}$ \\ ${ }^{1}$ Universidade Federal de Uberlândia, MG, Brasil.
}

\author{
Rodrigo Sanches Peres ${ }^{1}$ \\ ${ }^{1}$ Universidade Federal de Uberlândia, MG, Brasil.
}

Resumo: Como reflexo da reconfiguração da assistência em saúde mental proporcionada pela Reforma Psiquiátrica Brasileira, as oficinas terapêuticas vieram a se tornar, gradativamente, um dos principais dispositivos de tratamento nos Centros de Atenção Psicossocial (Caps). Porém, poucos estudos dedicados ao assunto elegeram como participantes profissionais de saúde responsáveis por oficinas terapêuticas. O presente estudo teve como objetivo compreender as concepções de um grupo de profissionais de saúde que coordenavam oficinas terapêuticas em Caps a respeito de tal prática. Trata-se de um estudo clínico-qualitativo, do qual participaram 12 profissionais de saúde que conduziam - à época da coleta de dados - oficinas terapêuticas em Caps de uma cidade do interior de Minas Gerais. A coleta de dados envolveu o recurso a uma entrevista semiestruturada e a um diário de campo. A análise de conteúdo foi a técnica aplicada ao corpus e levou à organização dos resultados em um conjunto de categorias e subcategorias. Nesta oportunidade, foram contempladas duas subcategorias, que abarcaram concepções sobre os objetivos e as especificidades das oficinas terapêuticas, e uma categoria, a qual tratou das concepções sobre a (não) adesão à referida prática. Em linhas gerais, os resultados revelam tanto aproximações quanto distanciamentos entre as concepções das participantes e a lógica do cuidado psicossocial preconizada pela Reforma Psiquiátrica Brasileira. Logo, o presente estudo reforça a necessidade de se fazer das oficinas terapêuticas objeto de reflexão permanente para que tal dispositivo de tratamento não venha a ser desfigurado.

Palavras-chave: Saúde Mental, Atenção Psicossocial, Oficinas Terapêuticas.

\section{Therapeutic Workshops and the Logic of Psychosocial Care: Conceptions of Coordinators}

\begin{abstract}
As a result of the mental healthcare reconfiguration prompted by the Brazilian Psychiatric Reform, therapeutic workshops gradually became one of the main treatment strategies in Psychosocial Care Centers (CAPS). However, few studies on the theme include health professionals responsible for therapeutic workshops as participants. This study aimed to understand the conceptions of 12 health professionals who were responsible for therapeutic workshops in CAPS regarding this practice. This is a clinical-qualitative study, in which participated 12 health professionals who were responsible - at the time of the data collection-for therapeutic workshops at Caps in a countryside city in Minas Gerais (Brazil). Data were collected using a semi-structured interview and a field diary. The resulting corpus underwent content analysis, being organized into a set of categories and subcategories. This study covered two subcategories addressing conceptions on therapeutic workshops objectives and particularities, and one category addressing conceptions related to (non-)adherence to this practice. The results reveal both approximations and gaps between participants' conceptions and the logic of psychosocial care recommended in the Brazilian Psychiatric Reform. Hence, this study reinforces the need for making therapeutic workshops an object of continuous reflection to avoid the disfigurement of this treatment.
\end{abstract}

Keywords: Mental Health, Psychosocial Care, Therapeutic Workshops. 


\title{
Los Talleres Terapéuticos y la Lógica del Cuidado Psicosocial: Concepciones de los/as Coordinadores/as
}

\begin{abstract}
Resumen: La reconfiguración de la atención en salud mental, mediante la Reforma Psiquiátrica Brasileña, posibilitó que los talleres terapéuticos se volviesen gradualmente uno de los principales dispositivos de tratamiento en los Centros de Atención Psicosocial (Caps). Pero son pocos estudios dedicados al tema que eligieron como participantes a los profesionales de salud responsables por talleres terapéuticos. Este estudio pretende comprender las concepciones de un grupo de profesionales de salud a cargo de la coordinación de talleres terapéuticos en Caps respecto a tal práctica. Este es un estudio clínico-cualitativo, en el cual participaron 12 profesionales de salud que ministraban - en el periodo de la recopilación de datos - talleres terapéuticos en Caps de una ciudad de Minas Gerais (Brasil). Para recopilar los datos se utilizó una entrevista semiestructurada y un diario de campo. El análisis de contenido fue la técnica aplicada al corpus y organizó los resultados en un conjunto de categorías y subcategorías. Dos subcategorías abarcaron concepciones sobre los objetivos y las especificidades de los talleres terapéuticos, y una categoría trató de las concepciones sobre la (no)adhesión a esa práctica. Los resultados revelan tanto aproximaciones como alejamientos entre las concepciones de las participantes y la lógica del cuidado psicosocial preconizada por la Reforma Psiquiátrica Brasileña. Por lo tanto, este estudio refuerza que es necesaria una reflexión permanente sobre los talleres terapéuticos para que ese dispositivo de tratamiento no se vea desfigurado.
\end{abstract}

Palabras clave: Salud Mental, Atención Psicosocial, Talleres Terapéuticos.

\section{Introdução}

A Reforma Psiquiátrica Brasileira pode ser compreendida como um processo direcionado tanto ao questionamento da assistência em saúde mental ofertada em consonância com o paradigma clássico da psiquiatria quanto à elaboração de propostas de transformação do modelo hospitalocêntrico, até então hegemônico no país (Amarante, 1995; Bezerra Jr., 2007). O processo em questão ganhou corpo na década de 1970, sendo que, conforme Hirdes (2009), se fundamentou na psiquiatria democrática, movimento que promoveu mudanças nos domínios legislativo, jurídico, administrativo e cultural que levaram à desconstrução do aparato manicomial em algumas cidades da Itália nos anos 1960. Porém, a autora sublinha que a inauguração do primeiro Centro de Atenção Psicossocial (Caps), já em 1987, na cidade de São Paulo, é considerada um dos mais importantes marcos práticos da implementação de serviços substitutivos em relação às instituições asilares no contexto nacional.

Outros serviços semelhantes surgiram de maneira gradativa pelo país e foram regulamentados somente no início da década de 1990, com a Portaria nº 224
(1992), a partir da qual todos eles - inclusive os Caps - passaram a ser tipificados como "unidades de saúde locais/regionalizadas, que oferecem atendimento de cuidados intermediários entre o regime ambulatorial e a internação hospitalar, em um ou dois turnos de quatro horas, por equipe multiprofissional" (p. 1). Entretanto, nove anos após a publicação de tal documento é que se promulgou a Lei no 10.216 (2001), que veio a estabelecer os direitos das pessoas com transtornos mentais. Logo, conclui-se que a Reforma Psiquiátrica Brasileira foi instituída legalmente após uma trajetória longa e permeada por diversos desafios, como observou Melo (2012).

Conforme Yasui, Luzio e Amarante (2016), a Reforma Psiquiátrica Brasileira, ao operacionalizar a assistência em saúde mental no território, visando a (re) inserção social e sempre primando pelo respeito às singularidades de cada usuário, viabilizou o efetivo exercício da lógica do cuidado psicossocial no país. E tal lógica parte do princípio de que o sofrimento psíquico não deve ser tomado como uma experiência individual, sendo que, por esse motivo, precisa ser metabolizado socialmente (Costa-Rosa, 2000). Os Caps têm contribuições 
extremamente significativas a oferecer neste sentido, pois se afiguram como serviços de saúde mental abertos, cujos objetivos essenciais são a promoção da autonomia dos usuários através do acesso ao trabalho e ao lazer e o fortalecimento de seus laços com a família e com a comunidade (Ministério da Saúde, 2004). Sendo assim, os Caps constituem um pilar da Reforma Psiquiátrica Brasileira (Mateus et al., 2008) e, por extensão, da lógica do cuidado psicossocial.

Atualmente, os Caps são regulamentados pela Portaria no 336 (2002), a qual ampliou o alcance e a complexidade desse tipo de serviço. Tal documento estipulou que os Caps devem se organizar em ordem crescente de porte e complexidade, podendo, inclusive, funcionar 24 horas por dia, como é o caso dos chamados Caps III, encontrados em municípios com população acima de 200 mil habitantes. Ademais, foi definido que compete a qualquer Caps oferecer três regimes de atendimento aos usuários, a saber: intensivo, semi-intensivo e não-intensivo. $\mathrm{O}$ atendimento intensivo acontece em todos os dias de funcionamento do serviço e geralmente é direcionado a pessoas com grave sofrimento psíquico, em situação de crise e dificuldades de convívio social. Já o atendimento semi-intensivo se destina aos usuários que apresentam melhora ou conseguem manter seus relacionamentos, mas ainda necessitam de atenção direta da equipe de saúde para atingir mais autonomia. $\mathrm{O}$ atendimento não-intensivo, por fim, é voltado aos casos para os quais o suporte oferecido pelo Caps não necessita ser contínuo.

Como corolário da Lei $\mathrm{n}^{\circ} 10.216$ (2001) e da Portaria no 336 (2002), o Projeto Terapêutico Singular (PTS) se consolidou como o principal instrumento de trabalho nos Caps, pois permite à equipe de saúde definir, a partir de discussões multidisciplinares, um conjunto de condutas articuladas especificamente frente às necessidades de cada caso (Ministério da Saúde, 2007). Oliveira (2008) salienta que, para construir um PTS, é preciso refletir sobre as atividades que estão sendo pensadas para cada usuário em específico, a fim de que se possa ter clareza, por exemplo, acerca de seus objetivos, de quais profissionais estarão envolvidos em seu desenvolvimento e de como e onde elas acontecerão. E cumpre assinalar que o usuário deve ser reconhecido como protagonista de seu próprio tratamento e, portanto, estimulado a participar ativamente da construção de seu PTS.
Também como reflexo da reconfiguração da assistência em saúde mental no Brasil, as oficinas terapêuticas vieram a se tornar, gradativamente, um dos principais dispositivos de tratamento nos Caps (Ministério da Saúde, 2004). Ressalte-se que as oficinas terapêuticas haviam sido preconizadas anteriormente pela Portaria no 224 (1992), já citada. Foram incluídas na tabela de procedimentos do Sistema de Informações Hospitalares do Sistema Único de Saúde (SUS) em 1991, por meio da Portaria no 189 (1991), cujo objetivo foi a "diversificação de métodos e técnicas terapêuticas voltadas a portadores de transtornos mentais" (p. 1). Entretanto, as oficinas terapêuticas se disseminaram mais significativamente após a publicação de uma cartilha do Ministério da Saúde, em 2004, na qual foram definidas como atividades a serem realizadas em grupo com a presença e orientação de um ou mais profissionais de saúde ou até mesmo de outras áreas, monitores e/ou estagiários, visando, basicamente, a promoção da (re)inserção social e da (re)integração familiar, a manifestação de sentimentos e dificuldades, o desenvolvimento de habilidades e o estímulo ao exercício da cidadania (Ministério da Saúde, 2004).

$\mathrm{Na}$ mesma cartilha, as oficinas terapêuticas foram divididas em três modalidades: expressivas, geradoras de renda e de alfabetização. As primeiras se caracterizam como um espaço em que variadas linguagens - como a pintura, o desenho, a dança, o teatro, a poesia e o canto - podem ser adotadas para incentivar, basicamente, a expressão plástica, corporal, verbal e/ou musical. As segundas têm como intuito a criação de produtos, por meio de atividades como a culinária, a marcenaria e a cerâmica, para comercialização e obtenção de retorno financeiro. As últimas, por fim, são destinadas especificamente aos usuários que não foram letrados e procuram fomentar a leitura e a escrita (Ministério da Saúde, 2004). É recomendável que cada Caps ofereça mais de uma modalidade de oficina terapêutica, pois somente assim cada usuário poderá decidir, juntamente com a equipe de saúde, se determinada oficina terapêutica será incluída ou não em seu PTS.

Para Galletti (2004), a beleza das oficinas terapêuticas estaria associada ao fato de admitirem múltiplos formatos. Porém, a autora sublinha que todos eles devem partir da premissa de que o respeito à singularidade dos usuários há de ser observado como diretriz principal. Já Almeida (2004) coloca em relevo 
a importância das oficinas terapêuticas ao afirmar que este dispositivo de tratamento preenche o espaço-tempo institucional e cria novas formas de intercâmbio com o território. Em contrapartida, Rauter (2000) adverte que, para que a lógica do cuidado psicossocial seja de fato colocada em ação nas oficinas terapêuticas, é imprescindível que proporcione, quer seja por meio do trabalho ou da arte, a superação do isolamento que caracteriza a vivência subjetiva da "loucura" e fortaleça a conexão dos usuários com “. . . o plano de imanência da vida, o mesmo plano com base no qual são engendradas a arte, a política e o amor" (p. 269).

No tocante à literatura consagrada às oficinas terapêuticas, faz-se necessário citar ainda as publicações de autoria de Lima (2008), Domingues e Paravidini (2009), Pádua e Morais (2010), Figueiró e Dimenstein (2010), Souza e Pinheiro (2012), Kinker e Imbrizi (2015), Nunes, Torres e Zanotti (2015) e Mendes, Lopes e Lobo (2016), dentre outras. Ressalte-se, inclusive, que uma recente revisão foi empreendida por Lima e Peres (2018) para estabelecer um panorama dos estudos veiculados no formato de artigo que tematizam tal prática. Os autores identificaram certa diversificação quanto aos objetivos visados e aos métodos empregados, mas constataram que poucos desses estudos elegeram como participantes profissionais de saúde que coordenam oficinas terapêuticas.

Não obstante, parece razoável propor que este dispositivo de tratamento eventualmente poderá, dependendo da coordenação, ser norteado de modo indevido por uma racionalidade mais próxima do paradigma clássico da psiquiatria do que da lógica do cuidado psicossocial preconizada pela Reforma Psiquiátrica Brasileira. Depreende-se, portanto, a relevância de pesquisas conduzidas junto a profissionais de saúde responsáveis por oficinas terapêuticas. Sendo assim, o presente estudo teve como objetivo compreender as concepções de um grupo de profissionais de saúde que coordenavam oficinas terapêuticas em Caps a respeito de tal prática. E cabe esclarecer que o termo "concepções" foi empregado em um sentido abrangente, porém, ancorado no corpo de conhecimentos da psicologia, para aludir ao resultado da integração de conceitos que surgem da atribuição de qualidades a algo e se relacionam entre si a partir de um denominador comum (Cabral \& Nick, 2006; Galimberti, 2002).

\section{Método}

\section{Desenho metodológico}

Trata-se de um estudo clínico-qualitativo, uma vez que o foco estabelecido, como apregoa Turato (2013), são fenômenos relativos ao setting dos cuidados com a saúde conforme descritos na perspectiva dos sujeitos envolvidos, quer sejam pacientes, familiares ou profissionais de saúde. O autor justifica tal foco sublinhando que é em torno do que os fenômenos representam - ou, em outras palavras, das concepções construídas sobre eles - que as pessoas organizarão suas vidas. Ademais, acrescenta que, nos termos da metodologia clínico-qualitativa, o pesquisador deve, sempre que possível, realizar a coleta de dados no local cotidiano de prestação de cuidados com a saúde, bem como, invariavelmente, reconhecer a importância da relação interpessoal que estabelece com os participantes. Logo, tais diretrizes metodológicas foram seguidas no presente estudo.

\section{Participantes}

Participaram do presente estudo 12 profissionais de saúde que coordenavam - à época da coleta de dados - oficinas terapêuticas em Caps de uma cidade do interior de Minas Gerais. Todos preencheram o único critério de inclusão estabelecido - possuir, pelo menos, seis meses de experiência com a referida prática em serviços de saúde mental abertos - e eram do sexo feminino. A idade das participantes variou de 25 a 58 anos, sendo que uma delas ocupava o cargo de assistente social e as demais trabalhavam como psicólogas. Ressalte-se que o número de participantes foi definido a partir da aplicação do critério de saturação, por meio do qual ocorre a interrupção da captação de novos participantes quando identificada, pelos pesquisadores, certa redundância nos resultados (Fontanella, Ricas, \& Turato, 2008).

\section{Instrumentos}

A coleta de dados envolveu o recurso a uma entrevista semiestruturada e a um diário de campo. Tal modalidade de entrevista - também chamada de semidirigida - permite ao participante modular a coleta de dados a partir das respostas que apresenta ao guia temático proposto pelo pesquisador e, justamente por essa razão, se sobressai como um instrumento fundamental no âmbito da metodologia clíni- 
co-qualitativa, como asseveram Fontanella, Campos e Turato (2006). No presente estudo, a entrevista semiestruturada foi direcionada por um roteiro composto por 20 questões abertas, relativas a tópicos de interesse para a consecução do objetivo estabelecido. Porém, é importante esclarecer que, seguindo as recomendações dos referidos autores, durante a coleta de dados foi permitido às participantes introduzirem outros tópicos que considerassem pertinentes, o que caracteriza uma alternância de diretividade.

Como advertem Nogueira-Martins e Bógus (2004), o pesquisador, ao realizar uma entrevista semiestruturada a fim de coletar de dados para uma pesquisa qualitativa, deve observar o comportamento não-verbal dos participantes para que venha a melhor compreender aquilo que foi comunicado verbalmente. Assim, um diário de campo foi adotado no presente estudo para operacionalizar o registro dessas observações. Trata-se, de acordo com Minayo (2014), de um instrumento de grande relevância em pesquisas qualitativas, também para coligir apontamentos sobre impressões pessoais relativas a quaisquer eventos presenciados pelo pesquisador no trabalho de campo e, então, complementar informações oriundas da utilização de outros instrumentos. Neste estudo, o diário de campo igualmente se prestou a essa finalidade mais ampla, no sentido de fomentar uma captação refinada da realidade empírica.

\section{Coleta de dados}

Dentre os seis Caps existentes na cidade em questão, a princípio um foi selecionado aleatoriamente. Após as devidas autorizações institucionais, todos os profissionais de saúde que coordenavam oficinas terapêuticas neste primeiro serviço e não se encontravam em férias ou afastamento quando do período reservado para a coleta de dados foram consultados sobre a possibilidade de participação no presente estudo. Verificou-se, então, que dois deles não somavam seis meses de experiência com a referida prática e, por essa razão, não foram considerados elegíveis. Os demais concordaram em participar. A seguir, outro Caps foi selecionado aleatoriamente. Também após as devidas autorizações institucionais, os profissionais de saúde que coordenavam oficinas terapêuticas nesse segundo serviço foram consultados, dessa vez, porém, um a um, até que o critério de saturação fosse atingido.
As participantes foram entrevistadas individualmente, em local reservado nas instalações dos Caps em que trabalhavam, em dias e horários definidos segundo a disponibilidade delas. As entrevistas foram gravadas em áudio, com a concordância prévia das participantes, após a aprovação do presente estudo por parte do Comitê de Ética em Pesquisa da instituição de filiação dos pesquisadores (parecer 1.957.085). Em média, as entrevistas duraram de 45 a 60 minutos. Ressalte-se que o acolhimento das participantes foi priorizado, a fim de favorecer o estabelecimento de um clima amigável para a coleta dados, sendo que todas elas demostraram atitude cordial durante as entrevistas. Ademais, conforme já detalhado, o diário de campo foi utilizado para registrar variados fenômenos, sempre o mais próximo possível do momento em que foram observados, mas não na presença das participantes, para evitar qualquer espécie de constrangimento.

\section{Análise de dados}

O corpus do presente estudo foi constituído, basicamente, pela transcrição, literal e na íntegra, das gravações em áudio das entrevistas. O diário de campo forneceu dados que complementaram aqueles derivados das entrevistas, a fim de conferir o devido contexto à análise empreendida, conectando-a mais diretamente ao universo no qual as participantes se encontravam inseridas e à relação interpessoal estabelecida para os fins da coleta de dados entre elas e a pesquisadora responsável por tal tarefa. A análise de conteúdo, nos termos propostos por Bardin (2016), foi a técnica aplicada ao corpus. Para a autora, a análise de conteúdo viabiliza a interpretação de variadas formas de discurso a partir de um processo que oscila entre ". . . os dois polos do rigor da objetividade e da fecundidade da subjetividade" (p. 15).

Faz-se necessário esclarecer que, no presente estudo, a circunscrição de unidades comparáveis procedimento metodológico básico da análise de conteúdo - se alicerçou em temas definidos pelo sentido das respostas das participantes. De acordo com Bardin (2016), o expediente em questão se presta, principalmente, à exploração de opiniões, atitudes e crenças - ou ainda concepções, como parece razoável acrescentar - que podem ser descobertas com o emprego de questões abertas, tendo sido selecionado precisamente por esta razão. O posterior reagrupamento das unidades comparáveis, por sua vez, foi pautado em catego- 
rias que reúnem elementos dotados de características comuns entre si. Ressalte-se também que, no presente estudo, as categorias derivam da classificação progressiva de tais elementos e foram validadas mediante a discussão dos resultados, realizada no âmbito do grupo de pesquisa ao qual pertencem os pesquisadores, acompanhando uma estratégia recorrentemente utilizada em pesquisas clínico-qualitativas.

\section{Resultados e discussão}

Antes de abordar os resultados derivados da análise de conteúdo, cabe sublinhar o fato de que apenas uma das participantes não ocupava o cargo de psicóloga. Tal achado, em certo aspecto, pode ser considerado inesperado, a julgar por três informações mencionadas anteriormente. Em primeiro lugar, porque o único critério de inclusão empregado no presente estudo foi possuir, pelo menos, seis meses de experiência com oficinas terapêuticas em serviços abertos de saúde mental. Em segundo lugar, porque os Caps, desde que foram regulamentados, devem contar com diferentes profissionais de saúde. Em terceiro lugar, por fim, porque as oficinas terapêuticas não se afiguram como uma prática exclusiva de um profissional em específico.

Contudo, pesquisas prévias - como aquelas conduzidas por Nunes et al. (2015), Souza e Pinheiro (2012), Jucá, Medrado, Safira, Gomes e Nascimento (2010) e Lima (2008) - sinalizam que é relativamente comum certa predominância de psicólogos(as) na coordenação de oficinas terapêuticas em Caps. É possível que tal tendência constitua um indicador da atualidade de um dos desafios da Reforma Psiquiátrica Brasileira elencados por Bezerra Jr. (2007) há mais de uma década: a efetiva incorporação de uma ampla gama de profissionais de saúde à assistência em saúde mental. Ademais, talvez represente também uma evidência de dificuldades quanto à ocupação do cargo de coordenador de oficinas terapêuticas por parte de profissionais de outras áreas - como artistas plásticos, atores e músicos - que poderiam desempenhar tal função.

Posto isso, faz-se necessário esclarecer que a análise de conteúdo levou à organização dos resultados em um conjunto de categorias e subcategorias. No presente estudo, serão contemplados aqueles referentes a duas subcategorias, que abarcaram concepções sobre os objetivos e as especificidades das oficinas terapêuticas, bem como a uma categoria, a qual tratou das concepções sobre a (não) adesão à referida prática. A primeira subcategoria revelou que, para diversas participantes, as oficinas terapêuticas deveriam ter como propósito central a promoção da (re) inserção social e da autonomia dos usuários, o que vai ao encontro da lógica do cuidado psicossocial. $\mathrm{O}$ relato 1 é representativo dessa concepção: “[A oficina terapêutica] seria uma modalidade de acompanhamento com vistas à busca da autonomia, com busca à inserção social . . . Então seria estratégias de cuidado terapêutico, de interação" (Participante 7).

Por outro lado, para duas participantes, os objetivos - específicos, ao menos - das oficinas terapêuticas seriam variáveis, pois dependeriam do PTS de cada usuário, como se vê no relato 2: "Uma oficina terapêutica, eu acho que é uma oficina que tem por objetivo melhorar em algum aspecto a qualidade de vida daquela pessoa, nem que seja naquele momento, sabe? Mas contribuir de alguma forma, com o Projeto Terapêutico dela" (Participante 8). Vale destacar que tal relato ainda sugere que o benefício proporcionado por uma oficina terapêutica eventualmente será circunstancial, possivelmente se resumindo à duração desse dispositivo de tratamento ou ao período de permanência no Caps.

Esses dois posicionamentos distintos, exemplificados pelos relatos 1 e 2, podem ser considerados ilustrativos da multiplicidade que, conforme Galletti (2004), é própria das oficinas terapêuticas. A autora adverte que não há um modelo rígido a ser seguido no desenvolvimento dessa prática, de modo que diversas estratégias e variadas linguagens podem ser empregadas. Por extensão, seria possível discriminar uma ampla gama de objetivos para as oficinas terapêuticas ou definir um objetivo mais unificador: fomentar a construção de novos projetos de vida por meio de um processo protagonizado pelo usuário. Para Kinker e Imbrizi (2015), é justamente isso que deve ocorrer para que o potencial terapêutico de uma oficina terapêutica possa ser efetivado. E parece razoável propor que a eventual adoção de uma postura mais restritiva a este respeito poderia acentuar os riscos de naturalização e aprisionamento desse dispositivo de tratamento, o que, obviamente, seria indesejável à luz das propostas da Reforma Psiquiátrica Brasileira.

Seria esperado que o PTS fosse apontado com maior frequência pelas participantes como norteador da definição dos objetivos específicos que as oficinas terapêuticas assumiriam para cada usuário. Afinal, é por meio da construção do PTS - processo no qual o usuário deve exercer papel ativo - que se programaria a presença em uma determinada oficina terapêutica em detrimento de outra (Pádua \& Morais, 2010). Mais do 
que isso, a operacionalização da assistência em saúde mental como um todo, em face dos avanços introduzidos pela Reforma Psiquiátrica Brasileira, passa pelo PTS, como estabelece o Ministério da Saúde (2007). Contudo, a maioria das participantes sinalizou que, comumente, tal diretriz não é observada nos serviços em que trabalham, como se pode depreender do relato 3 :

Olha, eu tenho percebido aqui que as oficinas são livres, né? São levados aos pacientes diariamente várias opções de atividades. E aí, dentro de um mesmo horário, de um mesmo espaço, funcionam várias oficinas diferentes, né? Outro dia a gente fez... tem gente pintando, tem gente fazendo colagem, trabalho com tecidos, trabalho com azulejos... então hoje em dia é mais livre... não tem nada preso....Ah, hoje é dia de isso, isso e tal... Amanhã é dia de tal... então tem uma liberdade para o usuário escolher o que que ele vai fazer... então acho que é uma atividade mais livre nesse sentido, né? (Participante 1).

Cumpre assinalar que outras participantes ainda declararam compreender que o desenvolvimento de qualquer oficina terapêutica deveria envolver a criação de algo material, concreto. O relato 4 é emblemático desta concepção: "A oficina... eu sempre lembro de oficina de algo... para mim fica muito a ideia de algo a ser produzido. De ser um momento e ter alguma produção daquele momento" (Participante 9). Em uma série de outros relatos, tal concepção não foi veiculada de maneira tão direta, mas se revelou nas entrelinhas, a julgar pelo fato de que diversas participantes, quando solicitadas a discorrer sobre as oficinas terapêuticas que coordenavam, optaram por uma caracterização baseada nas atividades realizadas. Essas atividades, tipicamente, se referiam à confecção de algum produto, como é possível observar no relato 5: "Nas minhas oficinas a gente faz tapete, faz bijuteria, faz mosaico... e o meu foco é mais na área do artesanato..." (Participante 4).

Tal achado pode ser considerado problemático, uma vez que remete a uma concepção hegemônica na década de 1920 e que alicerçava a "assistência em saúde mental" oferecida nas colônias agrícolas brasileiras. Afinal, nas instituições dessa natureza, diferentes atividades relativas às chamadas "ergoterapia" e "laborterapia" se afiguravam, concomitantemente, como o meio e o fim do tratamento (Andrade \& Costa-Rosa, 2014). Quando isso se repete no presente, as atividades acabam por promover uma ocupação "vazia" dos usuários, o que não é compatível com as finalidades das oficinas terapêuticas conforme estabelecidas pelo Ministério da Saúde. Portanto, fica nítido que, como alerta Rauter (2000), as oficinas terapêuticas eventualmente podem ensejar, ainda que de modo involuntário, o exercício da "velha psiquiatria".

Em contraste, Jucá et al. (2010) salientam que a confecção de algo material em uma oficina terapêutica é capaz de auxiliar no desenvolvimento de habilidades dos usuários, o que, por sua vez, tende a fazer com que eles se sintam mais produtivos. As autoras, contudo, destacam que as atividades selecionadas para tanto devem atender à diversidade de interesses dos usuários. Ademais, não necessariamente precisam acontecer nas instalações dos Caps. Aprofundando este último ponto, Kinker e Imbrizi (2015) enfatizam que a exploração do entorno por meio da realização de oficinas terapêuticas "extramuros" permite o estabelecimento de conexões mais consistentes com o território e, consequentemente, estimula a (re)inserção social dos usuários. Mas os autores alertam que a confecção de objetos, quando tomada como um fim em si mesmo em práticas que têm lugar dentro ou fora dos Caps, serve apenas ao controle social.

Já a segunda subcategoria, por meio da qual foram agregadas as concepções sobre as especificidades das oficinas terapêuticas, revelou que a distinção estabelecida pelo Ministério da Saúde entre oficinas terapêuticas expressivas, geradoras de renda e de alfabetização foi citada apenas pontualmente pelas participantes. Este achado também pode ser qualificado como problemático, até mesmo porque aparenta ser um desdobramento do fato de parte delas ter sugerido que o desenvolvimento de tal prática envolveria, via de regra, a produção de algo material. Logo, os limites existentes entre as diferentes modalidades de oficinas terapêuticas parecem ser pouco nítidos para a maioria das participantes. O relato 6 corrobora esta impressão ao sustentar que algumas delas conceberam que toda oficina terapêutica, por meio do recurso a diferentes atividades, teria caráter essencialmente expressivo:

Eu acho que a oficina é uma expressão. Eu defino como uma expressão. Écomo se, naquele momento, a pessoa dissesse de outras formas o que ela está sentindo. É lógico que tem as de artesanato, mas até nelas, o paciente quando está fazendo, ele está se expressando e ele vai te falando daquilo que ele está sofrendo (Participante 10). 
Em contrapartida, poucas participantes tipificaram mais apropriadamente como expressivas as oficinas terapêuticas que coordenavam, sendo que aquelas que o fizeram aludiram ao emprego de variadas linguagens artísticas selecionadas com o devido critério. Assim, demonstraram uma concepção sobre as especificidades das diferentes modalidades de oficinas terapêuticas mais alinhadas às diretrizes do Ministério da Saúde, o que pode ser qualificado como positivo. É válido reforçar que diversas pesquisas - Mendes et al. (2016), Souza e Pinheiro (2012) e Lima (2008), dentre outras-demonstram a importância da arte como veículo de expressão no contexto desse dispositivo de tratamento. Porém, como advertiram Domingues e Paravidini (2009), o fazer artístico pode ensejar apenas repetição quando uma oficina terapêutica é implementada com o mero intuito de ocupar e distrair os usuários.

Ademais, algumas participantes afirmaram coordenar oficinas terapêuticas que não se enquadram na categorização estabelecida pelo Ministério da Saúde. Parece razoável propor que, neste cenário, práticas inovadoras podem emergir, o que, em tese, seria interessante, contanto que não incorra em afastamento em relação à lógica do cuidado psicossocial. Porém, há que se considerar o risco de essas práticas se distanciarem mais facilmente dos objetivos para os quais foram inicialmente idealizadas. Isso porque a linguagem utilizada para o desenvolvimento das oficinas terapêuticas, nesses casos, foi adotada pelas participantes como único parâmetro para caracterizá-las. E, a princípio, uma "oficina de artesanato" tanto poderia ser expressiva quanto geradora de renda, bem como uma "oficina de poesia" comportaria como finalidade a expressão ou a alfabetização, por exemplo, a depender da forma como cada uma dessas linguagens é empregada.

Encerrando a segunda subcategoria, é preciso salientar que uma participante estabeleceu uma equivalência entre oficinas terapêuticas e grupos terapêuticos, fazendo-o por meio do relato 7: "Aqui no Caps eu faço um grupo terapêutico que é uma oficina, onde a gente... geralmente eu levo um tema, eu levo um assunto específico, e geralmente eu trabalho com conceitos, para que a gente debata sobre esses conceitos" (Participante 8). Obviamente, toda oficina terapêutica é realizada em grupo, mas a referida equivalência se revela controversa, sobretudo considerando que os grupos terapêuticos, tipicamente, são direcionados à abordagem de temas de caráter mais pessoal e/ou íntimo, o que geralmente não se observa nas oficinas terapêuticas. Contudo, Jucá et al. (2010) defendem que a polarização entre grupos terapêuticos e oficinas terapêuticas pode fomentar uma dicotomia entre questões pessoais e questões sociais ou entre dispositivos com enfoque clínico, por um lado, e enfoque político - que a Reforma Psiquiátrica Brasileira, na realidade, deveria combater.

Por fim, a categoria que tratou das concepções sobre a (não)adesão às oficinas terapêuticas evidenciou que, para a maioria das participantes, são preponderantes os fatores de natureza "interna", ou seja, que dizem respeito apenas aos próprios usuários, e não às atividades realizadas nas oficinas terapêuticas ou à coordenação. $\mathrm{O}$ (des)interesse dos usuários se destacaria com o principal fator "interno", segundo elas. Porém, algumas participantes igualmente salientaram a influência de uma menor disponibilidade circunstancial devido ao estado emocional de cada usuário. O relato 8 sintetiza tal concepção:

Tem alguns pacientes, também, que às vezes preferem ficar mais isolados, porque precisam de um momento mais sozinho mesmo. E, às vezes, naquele dia, ele não está bem, e aí não quer nada. Mas, no outro dia, ou na outra semana, já consegue participar, e começa a se envolver (Participante 2 ).

Uma participante aludiu a usuários que seriam refratários às oficinas terapêuticas em geral, como se vê no relato 9:

Olha, na minha [oficina terapêutica], a maioria tem adesão, mas sempre tem alguns que não ficam. Então, por exemplo, na minha tem sempre dois ou três que não aderem. E eu percebi também que não aderem a outras oficinas. A maioria deles, falaram que é porque eles não conseguem participar, ou não conseguem estar em grupo (Participante 6).

O fato de as participantes terem, basicamente, citado como determinantes para a (não) adesão às oficinas terapêuticas fatores relativos aos próprios usuários pode ser considerado preocupante, pois, em linhas gerais, é consistente com os resultados reportados por Figueiró e Dimenstein (2010) em uma pesquisa que se ocupou da dinâmica institucional em dois Caps. Ocorre que nesta pesquisa verificou-se a prevalência de um modo de funcionamento estático, definido exclusivamente pelos profissionais de saúde dos serviços em questão. Como consequência, muitos usuários se mos- 
travam apáticos e desinteressados em relação às oficinas terapêuticas, sugerindo uma falta de conexão entre os desejos e as necessidades destes e a assistência que lhes era ofertada. Portanto, os usuários deveriam poder participar mais ativamente da gestão dos serviços como um todo e, em especial, do planejamento das oficinas terapêuticas, conforme a recomendação das autoras.

Algumas participantes conceberam a existência de fatores "internos" especificamente fundamentados em diferenças de gênero que, supostamente, seriam responsáveis pela (não) adesão dos usuários às oficinas terapêuticas. Este achado também pode ser considerado preocupante, pois remete a concepções ultrapassadas sobre a assistência em saúde mental, que em nada se assemelham às premissas da Reforma Psiquiátrica Brasileira. Afinal, nos hospitais psiquiátricos brasileiros do final do século XIX e início do século XX, as atividades indicadas - ou impostas - aos pacientes, ao menos em parte, comumente eram determinadas pelo sexo: homens cultivavam a terra ou trabalhavam com couro ou madeira, ao passo que mulheres bordavam e costuravam, como apontam Santiago e Yasui (2011).

Poucas participantes mencionaram fatores de natureza "externa", isto é, relativos às próprias oficinas terapêuticas ou à coordenação, como decisivos para a (não)adesão dos usuários. E, quando o fizeram, recorreram a argumentos um tanto quanto vagos. Uma delas, por exemplo, defendeu que as atividades desenvolvidas nas oficinas terapêuticas deveriam "fazer sentido" para os usuários, e que o coordenador contribuiria para tanto relacionando-as à vida deles. Mas não esclareceu exatamente como essa relação poderia ser estabelecida ou reforçada. Outra participante sustentou a importância do "gosto" dos usuários pelas atividades e, adicionalmente, da "identificação" com o coordenador, sendo essa condição aparentemente determinada por uma mera questão de afinidade pessoal. Portanto, tratar-se-ia, na realidade, de um fator mais "interno" que "externo", ao contrário do que se poderia cogitar a partir de uma leitura inicial.

Cumpre assinalar que a atribuição de maior peso a fatores "internos" em termos da (não) adesão às oficinas terapêuticas espelha o fato de que, considerando-se o corpus como um todo, foi possível notar que, conforme as participantes, os usuários geralmente dispõem de poucas oportunidades para participar ativamente das decisões tomadas nos Caps em que são assistidos, embora tais decisões digam respeito diretamente a eles. Este fato se revelou "em nega- tivo", pois não houve sequer um relato que pudesse sinalizar alguma abertura quanto a tal participação. Logo, depreende-se uma verticalidade - semelhante àquela verificada na pesquisa de Figueiró e Dimenstein (2010) - das relações entre os usuários e os profissionais de saúde, pois estes parecem detentores da "palavra final" acerca do funcionamento dos serviços. De acordo com o Ministério da Saúde (2004), contudo, o protagonismo dos usuários é fundamental para que se alcancem os objetivos dos Caps e, assim, o cuidado psicossocial se efetive.

Algumas participantes ainda sugeriram que a (não) adesão às oficinas terapêuticas estaria relacionada, ainda que indiretamente, a um distanciamento deliberado, por parte dos familiares dos usuários, em relação ao cotidiano dos Caps. O relato 10 exemplifica uma queixa alusiva a tal problema: "Eu percebo assim, que por mais que é um Caps, eu percebo que as famílias querem trazer o paciente para cá, deixar, e é isso. É muito difícil contar com a participação da família" (Participante 9). Em contrapartida, cabe aos profissionais de saúde de qualquer Caps, em um primeiro momento, acolher a família em suas dificuldades para, em um segundo momento, trabalhar no sentido de fortalecê-la, visando a corresponsabilização do cuidado (Mielke, Kohlrausch, Olschowsky, \& Schneider, 2010). Parece razoável propor que, como desdobramento desse processo, os familiares teriam condições mais propícias para apresentar sugestões que poderiam vir a aprimorar as oficinas terapêuticas, estimulando, assim, a participação dos usuários.

\section{Considerações finais}

Como mencionado, buscou-se, com o presente estudo, compreender as concepções de um grupo de profissionais de saúde que coordenam oficinas terapêuticas em Caps a respeito desse dispositivo de tratamento e, com isso, fornecer elementos iniciais para o preenchimento de uma lacuna ainda existente na literatura científica. Os resultados proporcionados pela análise de conteúdo revelaram que, em consonância com a primeira subcategoria aqui contemplada, as oficinas terapêuticas, na perspectiva da maioria das participantes, devem ter como finalidade central a promoção da (re)inserção social e da autonomia dos usuários. Porém, para apenas duas delas o objetivo específico de tal prática variaria em função do PTS de cada usuário. Também foi frequente a concepção de que a produção de algo material é o intento de qualquer oficina terapêutica. 
A segunda subcategoria demonstrou, basicamente, que a distinção estabelecida pelo Ministério da Saúde entre oficinas terapêuticas expressivas, geradoras de renda e de alfabetização não é levada em conta pela maioria das participantes. Algumas delas, inclusive, afirmaram coordenar oficinas terapêuticas que não se enquadram nesta categorização, as quais, contudo, foram definidas pela linguagem utilizada para seu desenvolvimento, e não pelos objetivos para os quais foram idealizadas. Os achados veiculados nesta oportunidade ainda abarcaram uma categoria que, tratando das concepções sobre a (não) adesão ao dispositivo de tratamento em questão, tornou patente a valorização, entre as participantes, de fatores "internos". Logo, um usuário participaria ou não de uma determinada oficina terapêutica apenas movido por seu (des)interesse ou por diferenças de gênero, como se a atividade em si ou a coordenação pouco importassem.

Em suma: constataram-se tanto aproximações quanto distanciamentos entre as concepções das par- ticipantes e a lógica do cuidado psicossocial preconizada pela Reforma Psiquiátrica Brasileira. Logo, o presente estudo reforça a necessidade de se fazer das oficinas terapêuticas objeto de reflexão permanente, para que não venham a ser desfiguradas. Os resultados ora reportados igualmente evidenciam a necessidade de pesquisas futuras, até mesmo para que se possa verificar se, em outros contextos ou com a coordenação de tal prática a cargo de profissionais de saúde que não sejam psicólogos(as), o cenário que se apresenta é semelhante ou não. Ademais, o assunto se reveste de importância inquestionável, a julgar pelas ameaças de retrocessos associadas às recentes mudanças na política de saúde mental. De forma a viabilizar a superação de uma limitação do presente estudo, recomenda-se que, em pesquisas futuras, a coleta de dados também envolva a observação-participante de oficinas terapêuticas, a fim de viabilizar uma ampliação do recorte espacial procedido quanto ao trabalho de campo.

\section{Referências}

Almeida, N. (2004). Contribuições à tematização das oficinas nos Centros de Atenção Psicossocial. In C. M. Costa, \&A. C. Figueiredo (Orgs.), Oficinas terapêuticas em saúde mental: Sujeito, produção e cidadania (pp. 83-94). Contracapa.

Amarante, P. D. C. (1995). Loucos pela vida: A trajetória da Reforma Psiquiátrica no Brasil. Editora da Fiocruz.

Andrade, M. C., \& Costa-Rosa, A. (2014). O encontro da loucura com o trabalho: Concepções e práticas no transcurso da história. Gerais: Revista Interinstitucional de Psicologia, 7(1), 27-41.

Bardin, L. (2016). Análise de conteúdo (2a ed.). Edições 70.

Bezerra Jr., B. (2007). Desafios da reforma psiquiátrica no Brasil. Physis: Revista de Saúde Coletiva, 17(2), 243-250. https://dx.doi.org/10.1590/S0103-73312007000200002

Cabral, A., \& Nick, E. (2006). Dicionário técnico de Psicologia. Cultrix.

Costa-Rosa, A. (2000). O modo psicossocial: Um paradigma das práticas substitutivas ao modo asilar. In P. D. C. Amarante (Org.), Ensaios: Subjetividade, saúde mental, sociedade (pp. 141-168). Editora da Fiocruz.

Domingues, M. A., \& Paravidini, J. L. (2009). A construção de ofícios terapêuticos em saúde mental. Mental, 7(13), 39-59.

Figueiró, R. A., \& Dimenstein, M. D. B. (2010). O cotidiano de usuários de Caps: Empoderamento ou captura? Fractal: Revista de Psicologia, 22(2), 431-446. https://doi.org/10.1590/S1984-02922010000800015

Fontanella, B. J. B., Campos, C. J. G., \& Turato, E. R. (2006). Coleta de dados na pesquisa clínico-qualitativa: Uso de entrevistas não-dirigidas de questões abertas por profissionais da saúde. Revista Latino-Americana de Enfermagem, 14(5), 812-820. https://doi.org/10.1590/S0104-11692006000500025

Fontanella, B. J. B., Ricas, J., \&Turato, E. R. (2008). Amostragem por saturação em pesquisas qualitativas em saúde: Contribuições teóricas. Cadernos de Saúde Pública, 24(1), 17-27. http://dx.doi.org/10.1590/S0102-311X2008000100003

Galimberti, U. (2002). Diccionário de psicología. Siglo Veintiuno.

Galletti, M. C. (2004). Oficina em saúde mental: Instrumento terapêutico ou intercessor clínico? Editora da UCG.

Hirdes, A. (2009). A reforma psiquiátrica no Brasil: Uma (re)visão. Ciência \& Saúde Coletiva, 14(1), 297-305. http:// dx.doi.org/10.1590/S1413-81232009000100036 
Jucá, V. J. S., Medrado, A. C., Safira, L., Gomes, L. P. M., \& Nascimento, V. G. (2010). Atuação psicológica e dispositivos grupais nos Centros de Atenção Psicossocial. Mental, 8(14), 93-113.

Kinker, F. S., \& Imbrizi, J. M. (2015). O mito das oficinas terapêuticas. Polis e Psique, 5(3), 61-79. https:// doi.org/10.22456/2238-152X.58440

Lei $n^{\circ}$ 10.216, de 6 de abril de 2001. (2001, 9 de abril). Dispõe sobre a proteção e os direitos das pessoas portadoras de transtornos mentais e redireciona o modelo assistencial em saúde mental. Diário Oficial da União. http:// www.planalto.gov.br/ccivil_03/leis/leis_2001/110216.htm

Lima, A. F. (2008). Dependência de drogas e psicologia social: Um estudo sobre o sentido das oficinas terapêuticas e o uso de drogas a partir da teoria de identidade. Psicologia \& Sociedade, 20(1), 91-101. https://doi.org/10.1590/ S010271822008000100010

Lima, A. F. M., \& Peres, R. S. (2018). Entre o cuidado psicossocial e o passatempo: As oficinas terapêuticas no campo da saúde mental. Polêm!ca, 18(2), 105-118. https://doi.org/10.12957/polemica.2018.37791

Mateus, M. D., Mari, J. J., Delgado, P. G. G., Almeida-Filho, N., Barrett, T., Gerolin, J., Goihman, S., Razzouk, D., Rodriguez, J., Weber, R., Andreoli, S. B., \& Saxena, S. (2008). The mental health system in Brazil: Policies and future challenges. International Journal of Mental Health Systems, 2(12), 1-8. https://doi.org/10.1186/1752-4458-2-12

Melo, A. M. C. (2012). Apontamentos sobre a reforma psiquiátrica no Brasil. Cadernos Brasileiros de Saúde Mental, 4(9), 84-95.

Mendes, M. F., Lopes, V. B., \& Lobo, A. P. A. (2016). Saúde mental e arte: Relato de uma oficina de experiências estéticas em um centro de atenção psicossocial. Cadernos Brasileiros de Saúde Mental, 8(20), 69-79.

Mielke, F. B., Kohlrausch, E., Olschowsky. A., \& Schneider, J. F. (2010). A inclusão da família na atenção psicossocial: Uma reflexão. Revista Eletrônica de Enfermagem, 12(4), 761-765. https://doi.org/10.5216/ree.v12i4.6812

Minayo, M. C. S. (2014). O desafio do conhecimento: Pesquisa qualitativa em saúde (14a ed.). Hucitec.

Ministério da Saúde. (2004). Saúde mental no SUS: Os centros de atenção psicossocial. http:/ /www.ccs.saude.gov.br/ saude_mental/pdf/sm_sus.pdf

Ministério da Saúde. (2007). Clínica ampliada, equipe de referência e Projeto Terapêutico Singular (2a ed.). https:// bvsms.saude.gov.br/bvs/publicacoes/clinica_ampliada_2ed.pdf

Nogueira-Martins, M. C. F., \& Bógus, C. M. (2004). Considerações sobre a metodologia qualitativa como recurso para o estudo das ações de humanização em saúde. Saúde e Sociedade, 13(3), 44-57. https://doi.org/10.1590/ S0104-12902004000300006

Nunes, V. S., Torres, M. D. A., \& Zanotti, S. V. (2015). O psicólogo no Caps: Um estudo sobre oficinas terapêuticas. Estudos Contemporâneos da Subjetividade, 5(2), 135-146.

Oliveira, G. N. (2008). O Projeto Terapêutico Singular. In G. W. S. Campos \& A. V. Guerrero (Orgs.), Manual de práticas de atenção básica: Saúde ampliada e compartilhada (pp. 283-297). Hucitec.

Pádua, F. H. P., \& Morais, M. L. S. (2010). Oficinas expressivas: Uma inclusão de singularidades. Psicologia USP, 21(2), 457-478. https://doi.org/10.1590/S0103-65642010000200012

Portaria n. 189, de 19 de novembro de 1991. (1991). Aprova a inclusão de Grupos e Procedimentos da Tabela do SIH-SUS, na área de Saúde Mental (Hospitais Psiquiátricos). Ministério da Saúde. http://www.maringa.pr.gov.br/ cisam/portarial89.pdf

Portaria n. 224, de 29 de janeiro de 1992. (1992). Diretrizes e Normas para o Atendimento Ambulatorial/Hospitalar em Saúde Mental. Ministério da Saúde. http://www.maringa.pr.gov.br/cisam/portaria224.pdf

Portaria n. 336, de 19 de fevereiro de 2002. (2002). Ministério da Saúde. http://bvsms.saude.gov.br/bvs/saudelegis/ gm/2002/prt0336_19_02_2002.html

Rauter, C. (2000). Oficinas para que? Uma proposta ético-estético-política para oficinas terapêuticas. In P. D. C. Amarante (Org.), Ensaios: Subjetividade, saúde mental, sociedade (pp. 267-277). Editora da Fiocruz.

Santiago, E., \& Yasui, S. (2011). O trabalho como dispositivo de atenção em saúde mental: Trajetória histórica e reflexões sobre sua atual utilização. Revista de Psicologia da UNESP, 10(1), 195-210. 
Souza, L. G. S., \& Pinheiro, L. B. (2012). Oficinas terapêuticas em um Centro de Atenção Psicossocial: Álcool e drogas. Aletheia, (38-39), 218-227.

Turato, E. R. (2013). Tratado de metodologia da pesquisa clínico-qualitativa: Construção teórico-epistemológica, discussão comparada e aplicações nas áreas de saúde e humanas (6a ed.). Vozes.

Yasui, S., Luzio, C. A., \& Amarante, P. D. C. (2016). From manicomial logic to territorial logic: Impasses and challenges of psychosocial care. Journal of Health Psychology, 21(3), 400-408. https://doi.org/10.1177/ 1359105316628754

Ana Luiza de Mendonça Oliveira

Psicóloga e mestre em Psicologia pela Universidade Federal de Uberlândia (UFU), Uberlândia - MG. Brasil.

E-mail: ana.oliveiraluiza@gmail.com

(1) https://orcid.org/0000-0002-1921-3941

\section{Rodrigo Sanches Peres}

Professor do Programa de Pós-Graduação em Psicologia da Universidade Federal de Uberlândia (UFU), Uberlândia - MG. Brasil.

E-mail: rodrigosanchesperes@ufu.br

(1) https://orcid.org/0000-0002-2957-7554

Agradecimento:

À Coordenação de Aperfeiçoamento de Pessoal de Nível Superior (Capes), pelo financiamento parcial da pesquisa da qual deriva este artigo.

Endereço para correspondência:

Universidade Federal de Uberlândia. Instituto de Psicologia. Avenida Pará, 1720, Bloco 2C, CEP: 38400-902. Uberlândia - MG. Brasil.

Recebido 20/06/2018

Aceito 29/03/2019

Received 06/20/2018

Approved 03/29/2019

Recibido 20/06/2018

Aceptado 29/03/2019

Como citar: Oliveira, A. L. M., \& Peres, R. S. (2021). As oficinas terapêuticas e a lógica do cuidado psicossocial: Concepções dos(as) coordenadores(as). Psicologia: Ciência e Profissão, 41 (n.spe 4), 1-12.

https://doi.org/10.1590/1982-3703003204609

How to cite: Oliveira, A. L. M., \& Peres, R. S. (2021). Therapeutic Workshops and the Logic of Psychosocial Care: Conceptions of Coordinators. Psicologia: Ciência e Profissão, 41 (n.spe 4), 1-12.

https://doi.org/10.1590/1982-3703003204609

Cómo citar: Oliveira, A. L. M., \& Peres, R. S. (2021). Los talleres terapéuticos y la lógica del cuidado psicosocial: concepciones de los/as coordinadores/as. Psicologia: Ciência e Profissão, 41 (n.spe 4), 1-12. https://doi.org/10.1590/1982-3703003204609 